\title{
Is aerobic exercise useful to manage chronic pain?
}

\author{
Exercício aeróbico ajuda no tratamento da dor crônica?
}

\author{
Carolina Ortigosa Cunha ${ }^{1}$, Lívia Maria Sales Pinto-Fiamengui ${ }^{2}$, Fernanda Araújo Sampaio ${ }^{3}$, Paulo César Rodrigues Conti ${ }^{3}$
}

DOI 10.5935/1806-0013.20160015

\section{ABSTRACT}

BACKGROUND AND OBJECTIVES: Several studies have shown the importance of biopsychosocial strategies, including pharmacological and non-pharmacological therapies, to decrease pain in orofacial pain patients. The involvement of pain modulation during aerobic exercise contributes to the use of such modality as part of rehabilitation programs for chronic pain patients. Studies have shown that aerobic exercise may increase the level of several neurotransmitters, such as serotonin, dopamine, acetylcholine and norepinephrine. The reality is that it activates endocannabinoid and endogenous opioid systems, involved in pain modulation. The effect of physical activity on pain perception is often called exercise-induced hypoalgesia. This study aimed at discussing the use of exercise-induced hypoalgesia as part of chronic pain management, including orofacial pain.

CONTENTS: Comprehensive search on Pubmed, Medline, Web of Science and Scopus databases was carried out using the keywords: physical exercise, aerobic exercise, exercise-induced hypoalgesia, exercise-induced analgesia and orofacial pain/chronic orofacial pain.

CONCLUSION: Exercise does not need to be of high-intensity to have an effect on pain management. Although there is evidence that some chronic pain patients may have the capacity to exercise at intensities and durations that appear to be required to elicit exercise-induced hypoalgesia in healthy subjects, the exercise tolerance of other unhealthy populations requires study. Additional research is needed to clarify and expand the understanding of the mechanisms responsible for exercise-induced hypoalgesia and how it can be used in chronic pain conditions such as chronic orofacial pain.

Keywords: Chronic pain, Exercise, Exercise therapy, Orofacial pain, Pain management. \footnotetext{
tária, Bauru, SP, Brasil.

Submitted in November 30, 2015

Accepted for publication in January 23, 2016.

Conflict of interests: none - Sponsoring sources: none.

Correspondência to:

Carolina Ortigosa Cunha

Rua Irmã Arminda, 10-50 - Jardim Brasil

17011-160 Bauru, SP, Brasil.

E-mail: carol.ortigosa@gmail.com

(C) Sociedade Brasileira para o Estudo da Dor
}

1. Universidade do Sagrado Coração, Faculdade de Odontologia, Bauru, SP, Brasil. 2. Christus Centro Universitário, Faculdade de Odontologia, Fortaleza, CE, Brasil. 3. Universidade de Sáo Paulo, Faculdade de Odontologia, Departamento de Prótese Den-

\section{RESUMO}

JUSTIFICATIVA E OBJETIVOS: Vários estudos têm demonstrado a importância de utilização de estratégias biopsicossociais, incluindo terapias farmacológicas e não farmacológicas, para reduzir a dor em pacientes com dor orofacial. O envolvimento da modulação da dor durante o exercício aeróbico contribui para o uso dessa modalidade como parte de programas de reabilitação para pacientes com dor crônica. Estudos demonstram que o exercício aeróbico pode aumentar o nível de vários neurotransmissores tais como serotonina, dopamina, acetilcolina e norepinefrina. A realidade é que ele ativa os sistemas endocanabinóide e opioide endógeno, envolvidos no sistema de modulação de dor. O efeito da atividade física na percepçáo da dor é comumente denominado hipoalgesia induzida por exercício. O objetivo deste estudo foi discutir o uso do fenômeno da hipoalgesia induzida por exercício como parte do tratamento da dor crônica, incluindo a dor orofacial.

CONTEÚDO: Pesquisas abrangentes na base de dados Pubmed, Medline, Web of Science e Scopus foram realizadas utilizando as palavras-chave: exercício físico, exercício aeróbico, hipoalgesia induzida por exercício, analgesia induzida por exercício e dor orofacial/dor orofacial crônica.

CONCLUSÁO: $\mathrm{O}$ exercício não precisa ser de alta intensidade para se obter efeito sobre o controle da dor. Embora alguns estudos comprovem que alguns pacientes com dor crônica tem a capacidade de se exercitarem em intensidades e duraçóes de exercício que induzem a hipoalgesia induzida por exercício, a tolerância ao exercício e seus efeitos em populaçôes de pacientes crônicos ainda exigem mais estudos e investigaçóes para esclarecer e ampliar a compreensão do mecanismo da hipoalgesia induzida por exercício. Descritores: Dor crônica, Dor orofacial, Exercício, Manuseio da dor, Terapia por exercício.

\section{INTRODUCTION}

According to the International Association for the Study of Pain (IASP), pain is an unpleasant sensory and emotional experience associated with actual or potential tissue damage, or described in terms of such damage. It is always subjective once it is an emotional experience related to injuries in early life.

Pain may follow either acute or chronic course ${ }^{1}$. Iadarola and Cau$\mathrm{dle}^{2}$, stated that the acute pain, classified as "good" pain, has an important protective function for the organism. When this pain turns to chronic it is considered "bad pain" since no longer has the protective effect. Patients who suffer with chronic pain usually have an altered function of the central nervous system (CNS) that happens 
as result of persistent pathology or neuroplasticity changes ${ }^{3}$. Therefore, chronic pain is considered as a disease itself. According to IASP, it is the pain that persists past the healing phase following an injury. Chronic pain is associated with emotional and behavioral changes of the individual that suffers with it. Therefore, in order to have a better outcome, pain physicians should include the management of these aspects during chronic pain treatment.

Long-term conditions, such as chronic pain, result in psychological morbidity and impaired quality of life ${ }^{4}$. Pain modulation is part of the normal function of CNS, where the pain signal can be enhanced, inhibited or may remain the same at the brainstem level. When persistent nociceptive facilitation exceeds the inhibitory capacity, neuroplastic changes can occur peripherally or centrally and are known as peripheral sensitization and central sensitization, respectively 5 . CNS alterations, such as central sensitization and impaired descending modulatory mechanisms, contribute to the difficulties in chronic pain management.

Several studies have shown the importance of biopsychosocial management strategies, including pharmacological and non-pharmacological therapies, to reduce pain and improve function in orofacial pain patients ${ }^{6}$. However, there is a lack of real breakthrough innovation in the field of pain management over the past years ${ }^{7}$. According to Turk, Wilson and Cahana ${ }^{7}$, although there are massive efforts coming from basic science and clinical research to improve pain management, it remains a clinical challenge.

Exercise to reduce pain has been reported in the literature since the early $1980 \mathrm{~s}^{8-14}$ and the effect of physical activity on pain perception is commonly termed as exercise-induced hypoalgesia $(\mathrm{EIH})^{8}$. It has been shown that aerobic exercise may increase or optimize the levels of several neurotransmitters such as serotonin, dopamine, acetylcholine and norepinephrine. Indeed, it activates the endocannabinoid and endogenous opioid systems ${ }^{15,16}$. Conditioned pain modulation $(\mathrm{CPM})$ is another potential factor that could influence $\mathrm{EIH}$, especially given that exercise is sometimes perceived to be painful, especially isometric exercise. With CPM, pain from a noxious stimulus (conditioning stimulus, i.e., exercise) results in the inhibition of pain during the application of a second noxious stimulus (test stimulus) applied elsewhere (i.e., "pain inhibits pain"). The noxious conditioning stimulus activates descending inhibitory pathways, resulting in inhibition of extra-segmental spinal and trigeminal wide dynamic range neurons, thereby decreasing pain associated with the test stimulus ${ }^{17}$.

The involvement of pain modulation during aerobic exercise leads to the common use of this modality as part of rehabilitation programs for patients with chronic pain, including fibromyalgia, chronic neck pain, osteoarthritis, rheumatoid arthritis, and chronic low back pain ${ }^{15,16}$.

The purpose of this review article is to discuss the use of aerobic exercise and $\mathrm{EIH}$ as part of the management of chronic pain. Comprehensive searches at Pubmed, Medline, Web of Science and Scopus websites were undertaken using the key-words physical exercise, aerobic exercise, exercise-induced hypoalgesia, exercise-induced analgesia and orofacial pain/chronic orofacial pain.

\section{EXERCISE IN MANAGEMENT OF CHRONIC PAIN}

Pain information in the CNS is controlled by ascending and descending inhibitory systems using endogenous substances (neurotrans- mitters) as inhibitory mediators. As the nociceptive signal stimulates higher brainstem centers, it is modulated by inhibitory pathways that send signals downstream reducing the strength of the pain signal or if not completely eliminating $\mathrm{it}^{18}$.

Nowadays, aerobic exercise is part of the non-pharmacological approach in patients with chronic musculoskeletal orofacial pain ${ }^{19}$. Aerobic exercise programs reduce pain, fatigue and depression, and improve peak oxygen uptake, health-related quality of life and physical fitness in patients with fibromyalgia ${ }^{20,21}$. In chronic low back pain, aerobic endurance exercises are also commonly used and have been shown to reduce pain perception ${ }^{22}$. Even for migraine, exercise can improve pharmacological treatment. A recent study evaluated the association of amitriptyline and aerobic exercise for the treatment of sixty patients diagnosed with chronic migraine. In the aerobic exercise program patients were instructed to perform a 40 minutes fast walk outdoors with a frequency of 3 times/week for 12 consecutive weeks. The combination of amitriptyline and aerobic exercise was associated with an even greater reduction in the frequency, duration and intensity of headache ${ }^{23}$.

Studies have shown EIH (increased pain thresholds) after aerobic exercise for both mechanical ${ }^{22,24,25}$ and thermal stimuli ${ }^{26}$ and generalized increase of pressure pain thresholds following isometric muscle contraction $^{24,27}$.

Koltyn ${ }^{13}$ published a review article about analgesia following exercise describing the effect in animals and humans. According to the author, studies of exercise and analgesia started when researches observed that dancers and athletes could continue strenuous exercise in face of severe injuries, and later reported that they felt no pain. It has contributed to the notion that exercise can alter pain perception. Animal studies have shown the phenomenon of analgesia following exercise and the involvement of the endogenous opioid system. In the above-mentioned review, Koltyn observed that most researches investigated whether EIH is mediated by endogenous opioid mechanisms. According to the author, it appears from animal research that multiple analgesia systems exist (opioid and non-opioid) and that properties of the exercise stressor are important in determining which system is activated during exercise ${ }^{13,28}$. Blood pressure, cardiovascular system, CPM and endocannabinoid system are being studied as possible additional mechanisms involved with the EIH phenomenon ${ }^{29}$.

Ellingson et al. ${ }^{30}$ performed a study with sixteen healthy females to investigate the role of CPM as potential EIH mechanism. Volunteers completed a pain testing during three sessions: painful exercise, non-painful exercise, and quiet rest. Intensity and unpleasantness ratings to noxious heat stimuli were assessed at baseline, during and following each session. Results showed that the analgesic response was greater following painful exercise as compared to non-painful exercise in females. They concluded that EIH might involve the triggering of CPM via exercise-induced muscle pain. The greater the exercise-induced leg muscle pain, the greater the analgesic effect. Vaegter, Handberg and Graven-Nielsen ${ }^{31}$, performed a recent study, aiming at comparing CPM and EIH in chronic musculoskeletal pain patients with high widespread pain sensitivity as compared to low widespread pain sensitivity. Results of their study showed that even though groups had similar age, gender distribution, duration of pain, number of pain sites, clinical pain intensity and mood, 
CPM and EIH responses were partly impaired in patients with high pain sensitivity. At baseline, temporal summation of pain was more pronounced in patients with high pain sensitivity and it was further facilitated after aerobic exercise. Furthermore, CPM response was predicted by clinical peak pain intensity, which highlights the importance of ongoing pain in the process of pain inhibition. EIH response after aerobic exercise was predicted by CPM response after cold pressure test.

Galdino et al. ${ }^{32}$ performed a study with Wistar rats in which systemic and central pretreatment with CB1 and CB2 cannabinoid receptor antagonists (AM251 and AM630) blocked the antinociception induced by an aerobic exercise protocol in both mechanical and thermal nociceptive tests, at peripheral and central levels. Galdino's study has shown that the endocannabinoid system is involved in exercise-induced antinociception, similar to other analgesic systems. Further studies need to be performed looking at blocking both systems, opioid and endocannabinoid, simultaneously, to observe the specific role of each one in EIH.

Other studies observed dopamine and norepinephrine increase during exercise $\mathrm{e}^{33,34}$. Increased concentration of dopamine after exercise may simply be associated with stress produced by activity ${ }^{35}$. It is well known that stress activates different intrinsic pain inhibitory mechanisms, leading to hypoalgesia in humans and antinociception in rodents, a phenomenon referred to as stress-induced hypoalgesia/antinociception (SIA). Depending on the nature of stressors, different pain inhibitory mechanisms can be activated. In general, less severe stressors are thought to activate the endogenous opioid system and elicit the opioid-mediated form of stress-induced hypoalgesia ${ }^{36,37}$. Since exercise can be a stressor itself, both phenomena, EIH and SIA, could be contributing for the hypoalgesia following exercise, especially in healthy individuals.

\section{DISCUSSION}

Exercise type and dosage to best manage pain are not clear and may vary according to specific pain condition and patient tolerance. The magnitude and duration of exercise analgesia vary among studies. Although O'Connor and $\operatorname{Cook}^{14}$ stated in their review article that the effect of exercise in reducing pain appears to be most reliable following high intensity exercise and when the noxious stimulus is presented shortly after exercise, there has not been a systematic investigation of the duration and intensity of aerobic exercise that are necessary to produce an acute analgesic effect. High-intensity exercise performed for a short duration may produce hypoalgesia, but so may moderate-intensity exercise performed for a longer period. Hoffman et al. $^{38}$ and Koltyn et al. ${ }^{39}$ studied pain perception after exercise in healthy volunteers. Authors found that EIH was transient and lasted at least 15 minutes after aerobic exercise. Study results ${ }^{38}$ showed an analgesic effect 5 minutes after exercise, but the effect was not significant 30 minutes after aerobic exercise.

Recently, Bement and Sluka ${ }^{40}$ observed that moderate-intensity activity, such as walking, induces analgesia by opioid action in rats. A study conducted in humans concluded that exercise should exceed $50 \%$ of VO 2 max (maximum volume of oxygen) and last more than 10 minutes $^{41}$. For the same intensity and duration of exercise, those who regularly practice physical activity release exponentially more endorphins than sedentary individuals ${ }^{42}$.

Increased frequency, duration, and intensity of exercise are associated with less chronic pain according to Landmark et al. For individuals aging 20-64 years, the prevalence of chronic pain is $10-12 \%$ lower for those who exercise 1-3 times a week for at least 30 minutes or of moderate intensity, comparing to those who do not exercise. Depending on the load of exercise, the prevalence of chronic pain is $21-38 \%$ lower among older females who exercised comparing to those not exercising ${ }^{43}$.

Aerobic exercise in healthy individuals, such as running and cycling, has been examined most often, and a number of investigators have reported changes in pain perception during, as well as, following exercise. Walking can be recommended as an effective form of activity for individuals with chronic musculoskeletal pain but should be supplemented with strategies aimed at maintaining participation ${ }^{44}$. It is unclear whether individuals with chronic pain would experience similar results with exercise as healthy young adults. Results from studies examining EIH in individuals with chronic pain are currently equivocal, with EIH occurring in some chronic pain conditions (e.g, osteoarthritis, rheumatoid arthritis) but not consistently in others (e.g. fibromyalgia, temporomandibular disorders, painful diabetic neuropathy ${ }^{45}$. The dysfunctional (aerobic exercise activating pain facilitation rather than inhibition) endogenous analgesia during aerobic exercise is not a characteristic for all chronic pain patients, but limited to those with an evidence of central sensitization (e.g. chronic whiplash, fibromyalgia, chronic fatigue syndrome $)^{46}$.

The potential application of aerobic exercise as a form of pain management requires a comprehensive understanding of the intensity thresholds required to promote EIH. According to Naugle et al. ${ }^{47}$ not all individuals are willing or capable of engaging in high-intensity aerobic exercise. The authors confirm that moderate intensity aerobic exercise is likely insufficient to elicit EIH on healthy adults. However, they provided evidence that vigorous and moderate aerobic exercise reduce pain perception, with vigorous exercise producing better effects.

\section{CONCLUSION}

Exercise does not need to be of high-intensity or submaximal intensity to have an effect on pain management. The amount of studies performed in the past years have shown that aerobic exercise of moderate intensity, performed for more than 10 minutes can activate the endogenous mechanisms of pain control and pain modulation. Although there is evidence that some groups of chronic pain patients may have the capacity to exercise at intensities and durations that appear to be required to elicit EIH in healthy subjects, the exercise tolerance of other unhealthy populations requires study. Additional research is needed to clarify and expand the understanding of the mechanisms responsible for EIH and how it can be used in chronic pain conditions such as chronic orofacial pain.

\section{REFERENCES}

1. Merskey H, Bogduk N. Classification of chronic pain: descriptions of chronic pain syndromes and definitions of pain terms: IASP Press; 1994. 222p.

2. Iadarola JM, Caudle RM. Good pain, bad pain. Science. 1997;278(5336):239-40.

3. Yunus MB. Fibromyalgia and overlapping disorders: the unifying concept of central 
sensitivity syndromes. Semin Arthritis Rheum. 2007;36(6):339-56.

4. Zakrzewska JM. Multi-dimensionality of chronic pain of the oral cavity and face. J Headache Pain. 2013;14(1):37

5. de Leeuw R, Klasser GD. Orofacial Pain: Guidelines for assessment, diagnosis, and managment. American Academy of Orofacial Pain. $5^{\text {th }}$ ed. Chicago: Quintessence Publishing; 2013

6. Conti PC, Pinto-Fiamengui LM, Cunha CO, Conti AC. Orofacial pain and temporomandibular disorders: the impact on oral health and quality of life. Braz Oral Res. 2012;26(Suppl 1):120-3.

7. Turk DC, Wilson HD, Cahana A. Treatment of chronic non-cancer pain. Lancet. 2011;377(9784):2226-35.

8. Black J, Chesher GB, Starmer GA, Egger G. The painlessness of the long distance runner. Med J Aust. 1979;1(11):522-3.

9. Gurevich M, Kohn PM, Davis C. Exercise-induced analgesia and the role of reactivity in pain sensitivity. J Sports Sci. 1994;12(6):549-59.

10. Haier RJ, Quaid K, Mills JC. Naloxone alters pain perception after jogging. Psychiatry Res. 1981;5(2):231-2

11. Janal MN. Pain sensitivity, exercise and stoicism. J R Soc Med. 1996;89(7):376-81.

12. Janal MN, Colt EW, Clark WC, Glusman M. Pain sensitivity, mood and plasma endocrine levels in man following long-distance running: effects of naloxone. Pain. 1984;19(1):13-25.

13. Koltyn KF. Analgesia following exercise: a review. Sports Med. 2000;29(2):85-98.

14. O'Connor PJ, Cook DB. Exercise and pain: the neurobiology, measurement, and laboratory study of pain in relation to exercise in humans. Exerc Sport Sci Rev. 1999;27:119-66.

15. Deslandes A, Moraes H, Ferreira C, Veiga H, Silveira H, Mouta R, et al. Exercise and mental health: many reasons to move. Neuropsychobiology. 2009;59(4):191-8.

16. Matta Mello Portugal E, Cevada T, Sobral Monteiro-Junior R, Teixeira Guimarães T, da Cruz Rubini E, Lattari E, et al. Neuroscience of exercise: from neurobiology mechanisms to mental health. Neuropsychobiology. 2013;68(1):1-14.

17. Le Bars D, Willer JC. Diffuse noxious inhibitory controls (DNIC). In: Basbaum A, Bushnell MC, editors. Science of Pain. Oxford (UK): Elsevier; 2009. 763-73p.

18. Melzack R, Wall PD. Pain mechanisms: a new theory. Science. 1965;150(3699):971-9.

19. Overath CH, Darabaneanu S, Evers MC, Gerber WD, Graf M, Keller A, et al. Does an aerobic endurance programme have an influence on information processing in migraineurs? J Headache Pain. 2014;15:11.

20. Dinler M, Diracoglu D, Kasikcioglu E, Sayli O, Akin A, Aksoy C, et al. Effect of aerobic exercise training on oxygen uptake and kinetics in patients with fibromyalgia. Rheumatol Int. 2009;30(2):281-4.

21. Häuser W, Klose P, Langhorst J, Moradi B, Steinbach M, Schiltenwolf M, et al. Efficacy of different types of aerobic exercise in fibromyalgia syndrome: a systematic review and meta-analysis of randomised controlled trials. Arthritis Res Ther. 2010;12(3):R79.

22. Hoffman MD, Shepanski MA, Mackenzie SP, Clifford PS. Experimentally induced pain perception is acutely reduced by aerobic exercise in people with chronic low back pain. J Rehabil Res Dev. 2005;42(2):183-90.

23. Santiago MD, Carvalho Dde S, Gabbai AA, Pinto MM, Moutran AR, Villa TR. Amitriptyline and aerobic exercise or amitriptyline alone in the treatment of chronic migraine: a randomized comparative study. Arq Neuropsiquiatr. 2014;72(11):851-5.

24. Hoeger Bement MK, Dicapo J, Rasiarmos R, Hunter SK. Dose response of isometric contractions on pain perception in healthy adults. Med Sci Sports Exerc. 2008;40(11):1880-9.

25. Hoeger Bement MK, Weyer A, Hartley S, Yoon T, Hunter SK. Fatiguing exercise attenuates pain-induced corticomotor excitability. Neurosci Lett. 2009;452(2):209-13.
26. Staud R, Robinson ME, Price DD. Isometric exercise has opposite effects on central pain mechanisms in fibromyalgia patients compared to normal controls. Pain. 2005;118(1-2):176-84.

27. Kosek E, Lundberg L. Segmental and plurisegmental modulation of pressure pain thresholds during static muscle contractions in healthy individuals. Eur J Pain. 2003;7(3):251-8.

28. Koltyn KF. Exercise-induced hypoalgesia and intensity of exercise. Sports Med. 2002;32(8):477-87.

29. Koltyn KF, Brellenthin AG, Cook DB, Sehgal N, Hillard C. Mechanisms of exercise-induced hypoalgesia. J Pain. 2014;15(12):1294-304

30. Ellingson LD, Koltyn KF, Kim JS, Cook DB. Does exercise induce hypoalgesia through conditioned pain modulation? Psychophysiology. 2014;51(3):267-76.

31. Vaegter HB, Handberg G, Graven-Nielsen T. Similarities between exercise-induced hypoalgesia and conditioned pain modulation in humans. Pain. 2014;155(1):158-67.

32. Galdino G, Romero TR, Silva JF, Aguiar DC, de Paula AM, Cruz JS, et al. The endocannabinoid system mediates aerobic exercise-induced antinociception in rats. Neuropharmacology. 2014;77:313-24.

33. Droste C, Greenlee MW, Schreck M, Roskamm H. Experimental pain thresholds and plasma beta-endorphin levels during exercise. Med Sci Sports Exerc. 1991;23(3):334-42.

34. Schwarz L, Kindermann W. Beta-endorphin, adrenocorticotropic hormone, cortisol and catecholamines during aerobic and anaerobic exercise. Eur J Appl Physiol Occup Physiol. 1990;61(3-4):165-71.

35. Howells FM, Russell VA, Mabandla MV, Kellaway LA. Stress reduces the neuroprotective effect of exercise in a rat model for Parkinson's disease. Behav Brain Res. 2005;165(2):210-20.

36. Butler RK, Finn DP. Stress-induced analgesia. Prog Neurobiol. 2009;88(3):184-202.

37. Hohmann AG, Suplita RL, Bolton NM, Neely MH, Fegley D, Mangieri R, et al. An endocannabinoid mechanism for stress-induced analgesia. Nature. 2005;435(7045):1108-12.

38. Hoffman MD, Shepanski MA, Ruble SB, Valic Z, Buckwalter JB, Clifford PS. Intensity and duration threshold for aerobic exercise-induced analgesia to pressure pain. Arch Phys Med Rehabil. 2004;85(7):1183-7.

39. Koltyn KF, Garvin AW, Gardiner RL, Nelson TF. Perception of pain following aerobic exercise. Med Sci Sports Exerc. 1996;28(11):1418-21.

40. Bement MK, Sluka KA. Low-intensity exercise reverses chronic muscle pain in the rat in a naloxone-dependent manner. Arch Phys Med Rehabil. 2005;86(9):1736-40.

41. Hoffman R, Al'Absi M. The effect of acute stress on subsequent neuropsychological test performance (2003). Arch Clin Neuropsychol. 2004;19(4):497-506.

42. Souza JB. Can exercise induce analgesia in patients with chronic pain? Rev Bras Med Esporte. 2009;15(2):145-50.

43. Landmark T, Romundstad P, Borchgrevink PC, Kaasa S, Dale O. Associations between recreational exercise and chronic pain in the general population: evidence from the HUNT 3 study. Pain. 2011;152(10):2241-7.

44. O'Connor SR, Tully MA, Ryan B, Bleakley CM, Baxter GD, Bradley JM, et al Walking exercise for chronic musculoskeletal pain: systematic review and meta-analysis. Arch Phys Med Rehabil. 2015;96(4):724-34-e3.

45. Knauf MT, Koltyn KF. Exercise-induced modulation of pain in adults with and without painful diabetic neuropathy. J Pain. 2014;15(6):656-63.

46. Nijs J, Kosek E, Van Oosterwijck J, Meeus M. Dysfunctional endogenous analgesia during exercise in patients with chronic pain: to exercise or not to exercise? Pain Physician. 2012;15(3 Suppl):ES205-13.

47. Naugle KM, Naugle KE, Fillingim RB, Samuels B, Riley JL 3rd. Intensity threshold for aerobic exercise-induced hypoalgesia. Med Sci Sports Exerc. 2014;46(4):817-25. 